\title{
The last hadrosaurid dinosaurs of Europe: A new lambeosaurine from the Uppermost Cretaceous of Aren (Huesca, Spain)
}

\author{
Xabier Pereda-Suberbiola ${ }^{a}$, José Ignacio Canudo ${ }^{\mathrm{b}, *}$, Penélope Cruzado-Caballero ${ }^{\mathrm{b}}$, \\ José Luis Barco $^{c}$, Nieves López-Martínez ${ }^{\mathrm{d}}$, Oriol Oms ${ }^{\mathrm{e}}$, José Ignacio Ruiz-Omeñaca ${ }^{\mathrm{b}, \mathrm{f}}$ \\ ${ }^{a}$ Universidad del País Vasco/EHU, Facultad de Ciencia y Tecnología, Dpto. Estratigrafía y Paleontología, Apdo. 644, 48080 Bilbao, Espagne \\ ${ }^{\mathrm{b}}$ Grupo Aragosaurus - IUCA, Paleontología, Facultad de Ciencias, Universidad de Zaragoza, Pedro Cerbuna 12, 50009 Zaragoza, Espagne \\ c Paleoymás SL, Polígono Inbisa-Empresarium, Retama 17, Nave 24-C, 50720 La Cartuja Baja, Espagne \\ d Departamento de Paleontología, Facultad de Ciencias Geológicas, Universidad Complutense de Madrid, 28040 Madrid, Espagne \\ e Universitat Autònoma de Barcelona, Departament de Geologia, 08193 Cerdanyola-del-Vallès, Espagne \\ ${ }^{\mathrm{f}}$ Museo del Jurásico de Asturias (MUJA), 33328 Colunga, Espagne
}

Received 3 January 2009; accepted after revision 18 May 2009

Available online 25 July 2009

Presented by Philippe Taquet

\begin{abstract}
A new hadrosaurid dinosaur, Arenysaurus ardevoli gen. et sp. nov., from the Late Maastrichtian of Aren (Huesca, South-central Pyrenees) is described on the basis of a partial, articulated skull, mandibular remains and postcranial elements, including vertebrae, girdle and limb bones. Arenysaurus is characterized by having a very prominent frontal dome; nearly vertical prequadratic (squamosal) and jugal (postorbital) processes, and deltopectoral crest of the humerus oriented anteriorly. Moreover, it possesses a unique combination of characters: short frontal (length/width approximately 0.5 ); midline ridge of parietal at level of the postorbitalsquamosal bar; parietal excluded from the occiput; squamosal low above the cotyloid cavity. A phylogenetical analysis indicates that Arenysaurus is a rather basal member of Lambeosaurinae and the sister-taxon to Amurosaurus and the CorythosauriniParasaurolophini clade. The phylogenetic and biogeographical relationships of Arenysaurus and other lambeosaurines suggest a palaeogeographical connection between Asia and Europe during the Late Cretaceous. To cite this article: X. Pereda-Suberbiola et al., C. R. Palevol 8 (20no).
\end{abstract}

\section{Résumé}

Les derniers dinosaures hadrosauridés d'Europe : un nouveau lambéosauriné du Crétacé terminal d'Arén (Huesca, Espagne). Un nouveau dinosaure hadrosauridé, Arenysaurus ardevoli gen. et sp. nov., du Maastrichtien supérieur d'Arén (Huesca, Pyrénées méridionales) est décrit ici à partir d'un crâne partiel articulé, de restes mandibulaires et d'éléments postcrâniens, y compris des vertèbres et des os des ceintures et des membres. Arenysaurus est caractérisé par un dôme frontal très proéminent, par des processus postcotyloïde (squamosal) et jugal (postorbital) verticalisés et par une crête deltopectorale de l'humérus, orientée antérieurement. De plus, Arenysaurus montre une combinaison unique de caractères : frontal court (longueur/largeur environ 0,5); crête médiane du pariétal située au niveau de la barre postorbital-squamosal ; pariétal exclu de l'occiput; squamosal bas au-dessus

\footnotetext{
* Corresponding author.

E-mailaddresses: xabier.pereda@ehu.es (X. Pereda-Suberbiola), jicanudo@unizar.es (J.I. Canudo), penelope@unizar.es

(P. Cruzado-Caballero), jlbarco@ paleoymas.com (J.L. Barco), lopezmar@geo.ucm.es (N. López-Martínez), joseporiol.oms@uab.cat

(O. Oms), jigruiz@unizar.es (J.I. Ruiz-Omeñaca).

URL: http://www.aragosaurus.com (J.I. Canudo).
} 
de la cavité cotyloïde. Une analyse phylogénétique montre qu'Arenysaurus est un lambéosauriné plutôt basal et le groupe frère d'Amurosaurus et du clade Corythosaurini-Parasaurolophini. Les relations phylogénétiques et biogéographiques d'Arenysaurus et d'autres lambéosaurinés suggèrent une connexion paléogéographique entre l'Asie et l'Europe, au cours du Crétacé supérieur. Pour ritor rot artislo - X Poreda-Suberbiola et al., C. R. Palevol 8 (2009).

Keywords: Hadrosauridae; Arenysaurus ardevoli nov. gen. et sp.; Maastrichtian; Huesca; Iberian Peninsula

Mots clés : Hadrosauridae ; Arenysaurus ardevoli nov. gen. et sp. ; Maastrichtien ; Huesca ; Péninsule ibérique

\section{Introduction}

The fossil record of Iberian hadrosaurids is probably the best of Europe. Of nearly 50 localities of Late Cretaceous age (Campanian-Maastrichtian) known in Europe, almost the half are located in the Iberian Peninsula and more specifically in the South-central Pyrenees of Lleida (Catalonia) and Huesca (Aragón), in Spain. In spite of the large amount of remains discovered in the last years, only a part is available for study (numerous bones are still unprepared) and skull material remains rare. Consequently, only one Iberian named species is widely accepted: Pararhabdodon isonensis from the Maastrichtian of the Tremp Formation, in Lleida [3]. The status of Koutalisaurus kohlerorum, a species recently erected on the basis of a dentary previously ascribed to $P$. isonensis [29], remains uncertain [28]. At least three different hadrosauroid taxa are known in the Upper Maastrichtian formations of the Iberian Peninsula, though they are indeterminate at the genus and species level $[20,28]$. Other hadrosaurid species from the European Cretaceous archipelago that are represented by relatively complete cranial material are Telmatosaurus transsylvanicus from the Maastrichtian of Transylvania, in Romania [6,35], and an unnamed hadrosaurid from the Santonian-Campanian of Trieste, NE Italy [6].

Here we describe a new genus and species of hadrosaurid dinosaur from the Latest Cretaceous (Late Maastrichtian) of Aren (Huesca, Spain). Significant cranial remains, including the best preserved skull of western European hadrosauroids, and associated postcranial bones, represent the new taxon. The phylogenetical and palaeobiogeographical implications of this discovery are also discussed.

\section{Methods}

\subsection{Terminology}

The node-based definition of Hadrosauridae used here is "the clade consisting of Telmatosaurus and
Parasaurolophus, their most recent common ancestor and all descendants" [19,35]. Other authors $[11,29,31]$ have argued for a more restrictive definition of Hadrosauridae: "Lambeosaurinae plus Hadrosaurinae and their most recent common ancestor" (=Euhadrosauria [35]). The stem-based definition of Lambeosaurinae is: "all hadrosaurids more closely related to Parasaurolophus than to Saurolophus" and that of Hadrosaurinae, "all hadrosaurids more closely related to Saurolophus than to Parasaurolophus" [31]. Within lambeosaurines, Corythosaurini are "all taxa more closely related to Corythosaurus than to Parasaurolophus", and Parasaurolophini "all taxa more closely related to Parasaurolophus than to Corythosaurus" [8]. Finally, Hadrosauroidea can be defined as "all iguanodontians more closely related to Parasaurolophus than to Iguanodon" [31].

\subsection{Institutional abbreviations}

BMNH: The Natural History Museum, London, U.K.; MPZ: Museo Paleontológico de la Universidad de Zaragoza, Gobierno de Aragón, Zaragoza, Spain.

\section{Geological and chronological frame}

The vertebrate-bearing localities of Aren (NE Huesca, Spain, Fig. 1) are exposed along the northern limb of the Tremp syncline, in the South-central Pyrenean unit. They are situated west of the village of Aren and near the Blasi Hill. The fossiliferous sites have been numbered Blasi 1 to Blasi 5 [20]. Blasi 1 is located on the top of the Aren Sandstone (Fig. 2) whereas the other sites are located in the lower part of the overlying Tremp Formation. These sites occur in delta-front, lagoonal and coastal deposits of the Aren 4 depositional sequence $[1,20]$.

The hadrosaurid material described here comes from the Blasi 3 site, which is the richest one in vertebrate fossils. It is situated in a 1-m thick grey massive calcareous sandstone containing Ophiomorpha burrows. Blasi 3 and the other Blasi sites are physically correlated with basinal 


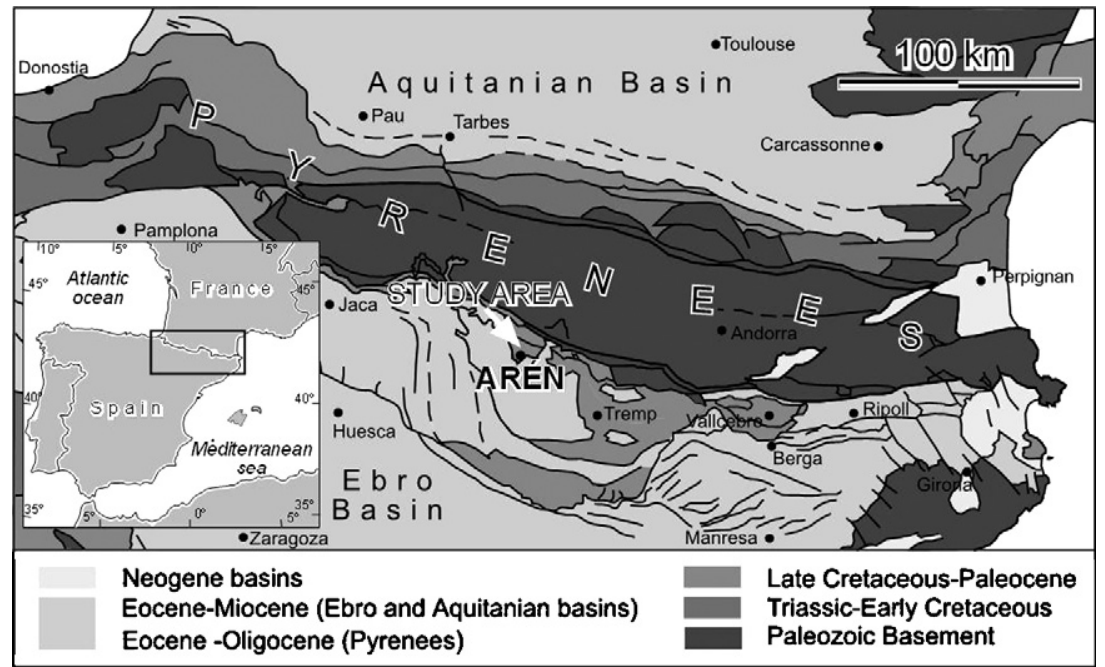

Fig. 1. Map showing the location of the Blasi sites in Aren (Huesca, South-central Pyrenees).

Fig. 1. Carte montrant l'emplacement des localités de Blasi à Arén (Huesca, Pyrénées sud-centrales).

marine strata containing planktonic foraminifera from the Upper Maastrichtian Abathomphalus mayaroensis Biozone [20]. This zone embraces an age interval from -68.4 to $-65.5 \mathrm{Ma}$ (new K/T boundary age) [18].

A refinement of the undisputed Late Maastrichtian age of the Blasi sites was later carried out using magnetostratigraphy [25]. All palaeontological sites of Blasi are located in a normal polarity chron correlated to chron C30n (GPTS dated from -67.6 to $-65.5 \mathrm{Ma}$ ) [2]. In the present study, we improve the existing magnetostratigraphic data (Fig. 2) by adding few more samples and displaying them in their statigraphic succession from two separate sections. Clear normal polarities are recorded at the top of the offshore Salas Marls and in the timetransgressive Aren Formation, as well as in the lower part of the Tremp Formation. After some meters of section of undetermined polarity, the rest of the section displays reverse polarities until the top of our section.

The vertebrate remains of Blasi 3 have been found in an area of about 70 square meters, most of them belonging to hadrosaurid ornithopods. A partial skull, lower jaw remains with teeth and associated, partially articulated postcranial (vertebral and appendicular) elements from presumably a sole adult individual (Fig. 4 in [20]) are here referred to a new genus and species of lambeosaurine hadrosaurid. In addition, sacral vertebrae and pelvic girdle remains of a juvenile lambeosaurine [5] and of a small adult hadrosaurid not yet studied have been found in Blasi 3. Isolated teeth from large theropod dinosaurs, crocodyliform bones (provisionally referred to alligatoroids) and turtle plates (similar to those of the bothremydid Polysternon) are also known [20]. The presence of articulated hadrosaurid remains in Blasi 3 probably indicates a rapid burial.

\section{Systematic palaeontology}

Dinosauria Owen, 1842

Ornithischia Seeley, 1887

Ornithopoda Marsh, 1881

Hadrosauridae Cope, 1869

Lambeosaurinae Parks, 1923

Arenysaurus gen. nov.

\subsection{Etymology}

From Aren (Areny de Noguera in Catalonian language), the village of Huesca province (Spain) located near the area where the fossils were found.

\subsection{Diagnosis}

As for the type and only known species.

\subsection{Type species}

\section{Arenysaurus ardevoli.}

Arenysaurus ardevoli sp. nov.

\subsection{Holotype}

MPZ 2008/1, a partial, articulated skull comprising the skull roof and braincase. 


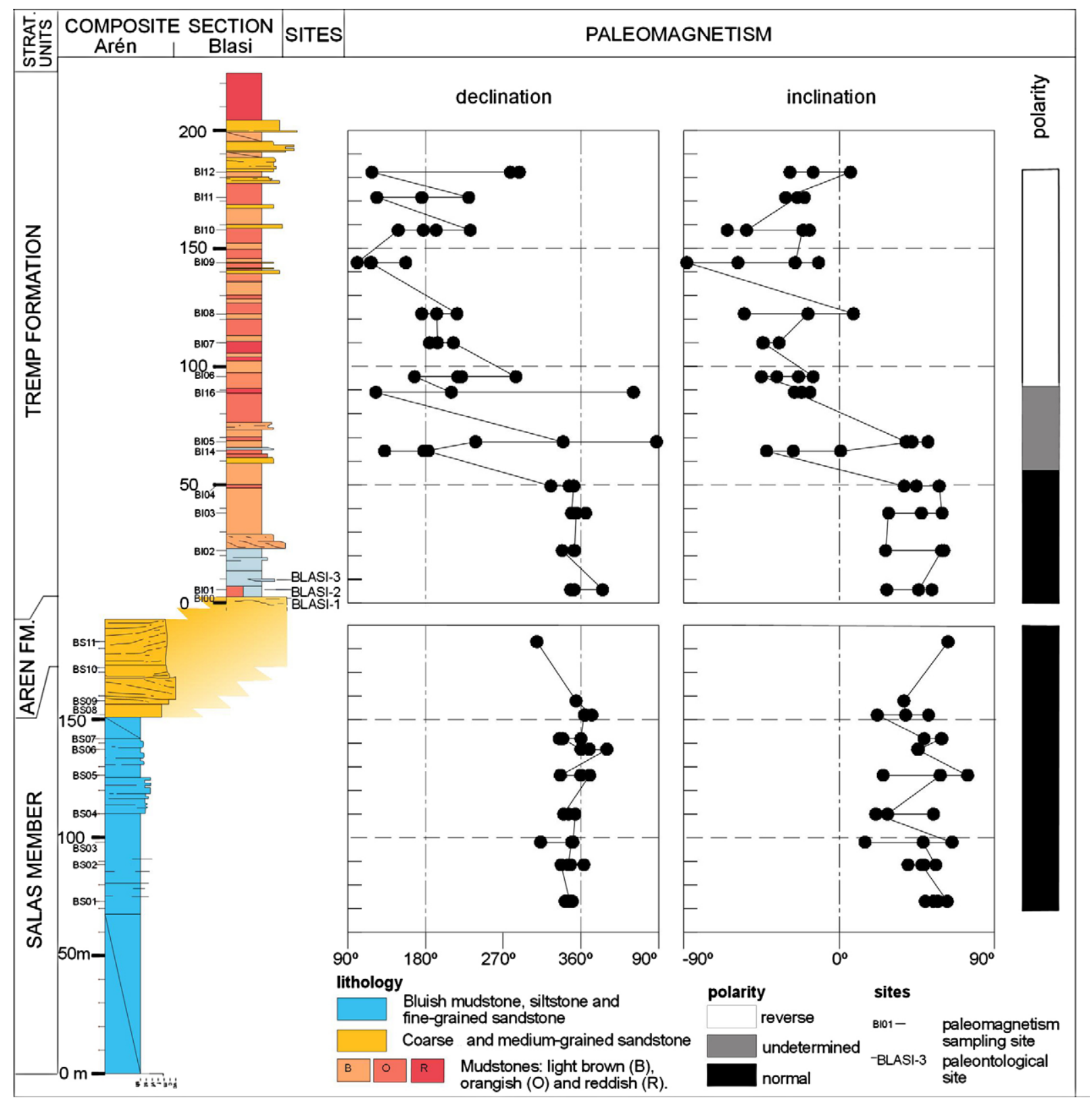

Fig. 2. Blasi (left) and Aren (right) stratigraphic sections (Huesca), with the location of the Blasi 1-3 sites, palaeomagnetic ChRM declination and inclination data and polarity zones. The diachronic distribution of the Aren Formation [1] impedes a more accurate correlation between both sections.

Fig. 2. Coupes stratigraphiques de Blasi (à gauche) et d'Arén (à droite) (Huesca), avec la position de Blasi 1-3, les données de la déclinaison et de l'inclinaison paléomagnétiques (ChRM), ainsi que les magnétozones. La distribution diachronique de la formation Arén [1] empêche une corrélation plus exacte entre les deux sections.

\subsection{Etymology}

In honour of the geologist Lluis Ardèvol (Geoplay, Tremp, Lleida), who discovered the Blasi sites.

\subsection{Type locality and horizon}

Blasi 3 site in Aren (Huesca, Spain); lower part of the Tremp Formation; Late Cretaceous, Late Maas- 


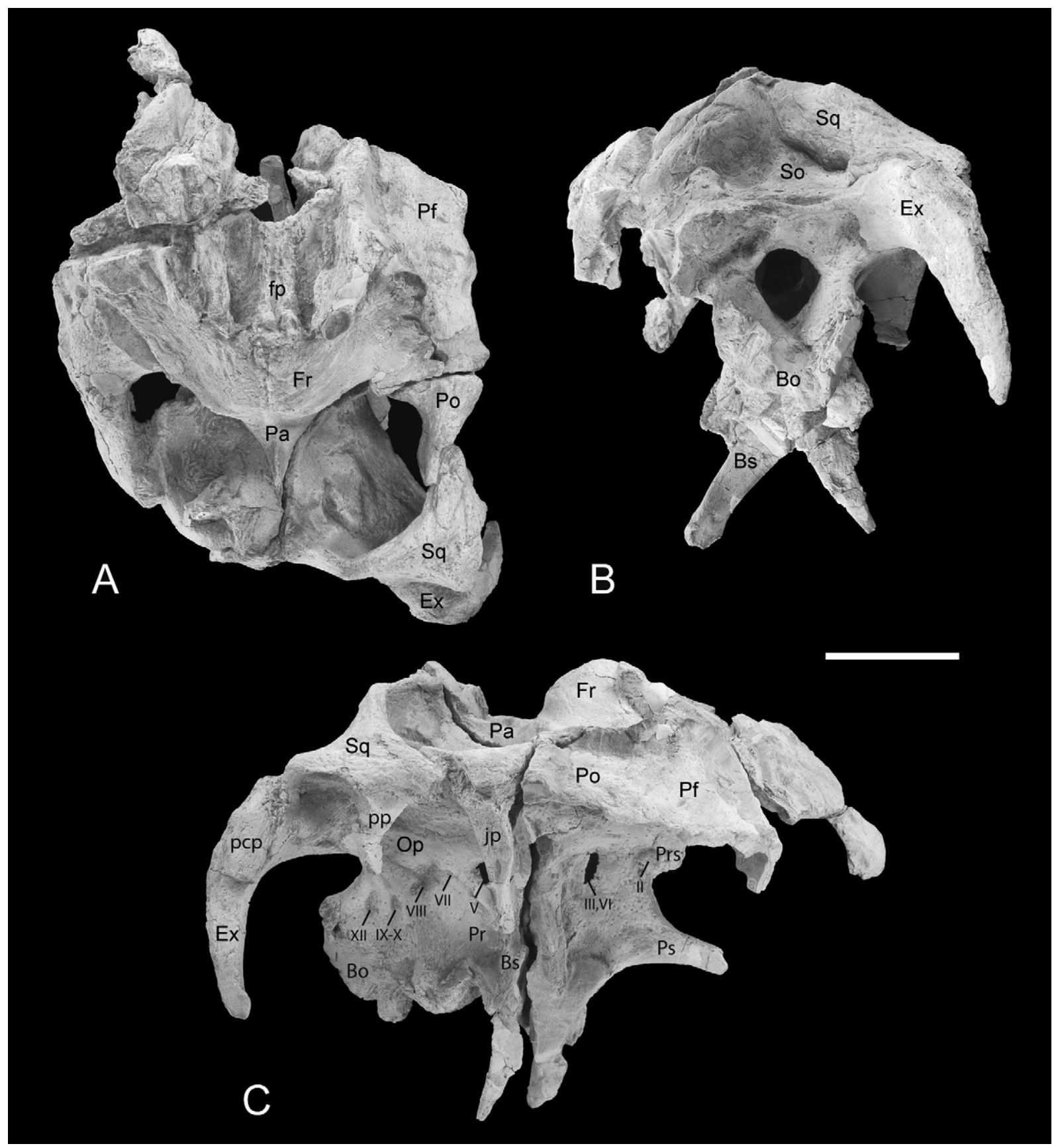

Fig. 3. Arenysaurus ardevoli nov. gen. et sp. from the Late Maastrichtian of Huesca, Spain. Articulated partial skull MPZ2008/1 (holotype) in dorsal (A), posterior (B) and right lateral (C) views. Abbreviations: Bo: basioccipital; Bs: basisphenoid; Ex: exoccipital; fp: frontal platform; Fr: frontal; jp: jugal process; Op: opisthotic; Pa: parietal; pcp: postcondylar process; Pf: prefrontal; Po: postorbital; pp: prequadratic (precotyloid) process; Pr: prootic; Ps: parasphenoid; So: supraoccipital; Sq: squamosal; II to XII, foramina for cranial nerves. Scale equals to $50 \mathrm{~mm}$.

Fig. 3. Arenysaurus ardevoli nov. gen. et sp. du Maastrichtien supérieur de Huesca, Espagne. Crâne incomplet articulé MPZ2008/1 (holotype) en vues dorsale (A), postérieure (B) et latérale droite (C). Abréviations : Bo : basioccipital; Bs : basisphénoïde ; Ex : exoccipital ; fp : plate-forme du frontal ; Fr : frontal ; jp : processus jugal ; Op : opisthotique; Pa : pariétal ; pcp : processus postcondylaire ; Pf : préfrontal ; Po : postorbitaire ; pp : processus préquadratique (précotyloïde); Pr: prootique; Ps : parasphénoïde; So : supraoccipital ; Sq : squamosal ; II à XII : foramens pour les nerfs crâniens. Échelle : $50 \mathrm{~mm}$. 


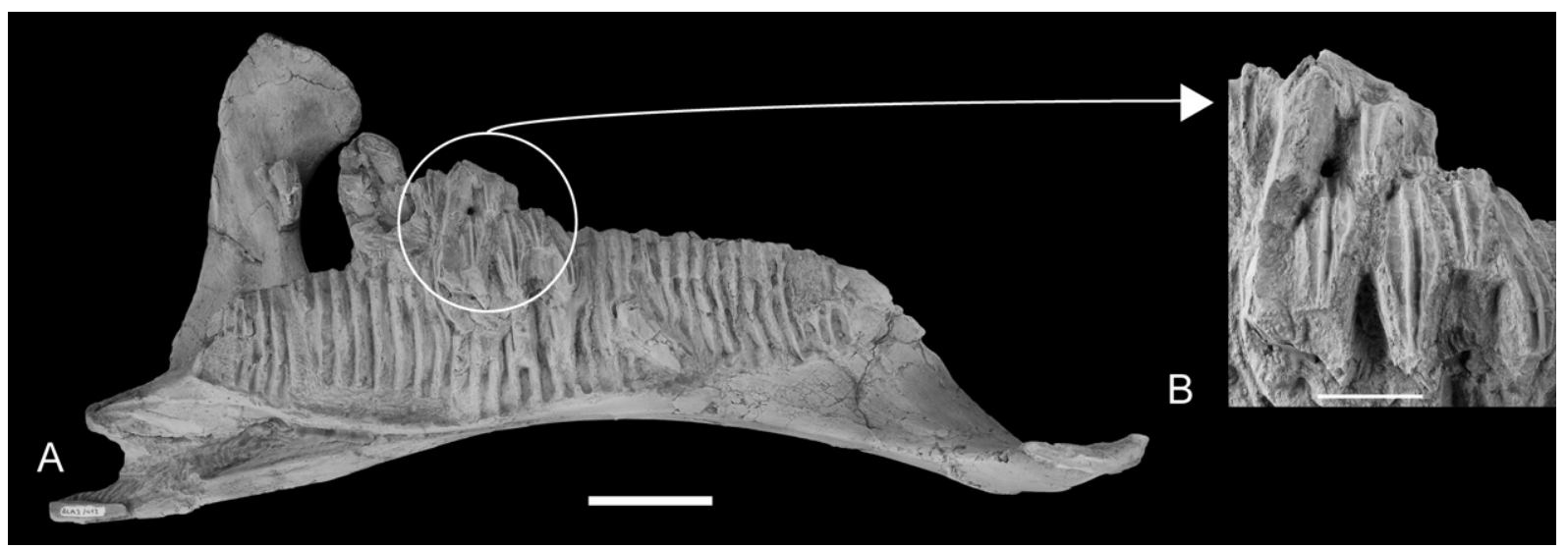

Fig. 4. Arenysaurus ardevoli nov. gen. et sp. from the Late Maastrichtian of Huesca, Spain. Left dentary (A) with a small portion of the dental battery (B) MPZ2008/258 (paratype) in medial view. Scale equals to $50 \mathrm{~mm}$.

Fig. 4. Arenysaurus ardevoli nov. gen. et sp. du Maastrichtien supérieur de Huesca, Espagne. Dentaire gauche (A) avec une partie de la batterie dentaire (B) MPZ2008/258 (paratype) en vue médiale. Échelle : $50 \mathrm{~mm}$.

trichtian (upper part of chron 30n) ([20,25]; this work) (Figs. 1 et 2).

\subsection{Diagnosis}

Lambeosaurine hadrosaurid characterized by a very prominent frontal dome, more developed than in other adult specimens; nearly vertical prequadratic process of the squamosal and jugal process of the postorbital; deltopectoral crest of the humerus oriented anteriorly. Differs from other lambeosaurines in having a unique combination of characters: short frontal, with a posterior length/with ratio estimated at 0.5 ; midline ridge of parietal approximately at the level of the postorbitalsquamosal bar; parietal not interposed between the squamosals in the occipital surface of the skull; lateral side of squamosal relatively low above the cotyloid cavity.

\subsection{Paratypes}

Cranial: MPZ2008/256, fragmentary right maxilla; MPZ2008/257, fragmentary left maxilla; MPZ2008/ 258, left dentary with 12 teeth; MPZ2008/259, right surangular; MPZ2008/260-263, four isolated teeth. Postcranial skeleton: MPZ2007/706, MPZ2007/954955, MPZ2008/264-267, seven cervical vertebrae; MPZ2008/268, dorsal vertebra; MPZ2008/269-270, two dorsal ribs; MPZ2008/271, partial sacrum with ossified tendons; MPZ2004/480, pathological caudal vertebra; MPZ2006/20, 14 articulated caudal vertebrae and chevrons; MPZ2008/272, 313, two caudal vertebrae; MPZ2008/314, 330, haemal archs; MPZ2008/331-
332, two ossified tendons; MPZ2008/333a-b, right scapula (two fragments); MPZ2008/334, right coracoid; MPZ2008/336, right humerus; MPZ2008/335, fragmentary right ilium; MPZ 2007/707, right pubis; MPZ 2007/711, right femur; MPZ2008/337 left femur.

\section{Description and discussion}

\subsection{Skull}

The incomplete but finely preserved skull of Arenysaurus ardevoli (MPZ2008/1, holotype) (Fig. 3) consists of prefrontal, frontal, parietal, postorbital, squamosal, supraoccipital, exoccipital-opisthotic complex, prootic, basioccipital, basisphenoid, parasphenoid, laterosphenoid, orbitosphenoid and presphenoid bones. Elements of the rostral region of the facial skeleton and the palatoquadrate complex are missing. The skull is relatively deep dorsoventrally and anteroposteriorly shortened; this results in a roughly quadrangular skull in dorsal view (Fig. 3A). The right side of the skull is better preserved than the left one that suffered from deformation (supratemporal fenestra) and postdepositional breakage (i.e., left paroccipital process, occipital condyle). As preserved, the skull is approximately $250 \mathrm{~mm}$ long; the estimated total skull length is of approximately $600 \mathrm{~mm}$.

The hollow supracranial crest commonly seen in lambeosaurines is not preserved in MPZ2008/1. However, its presence can be inferred from the posterior half of the craniofacial skeleton, which is highly modified to accommodate such a structure (e.g., shortened frontals and parietals, deeply excavated frontal platform; 


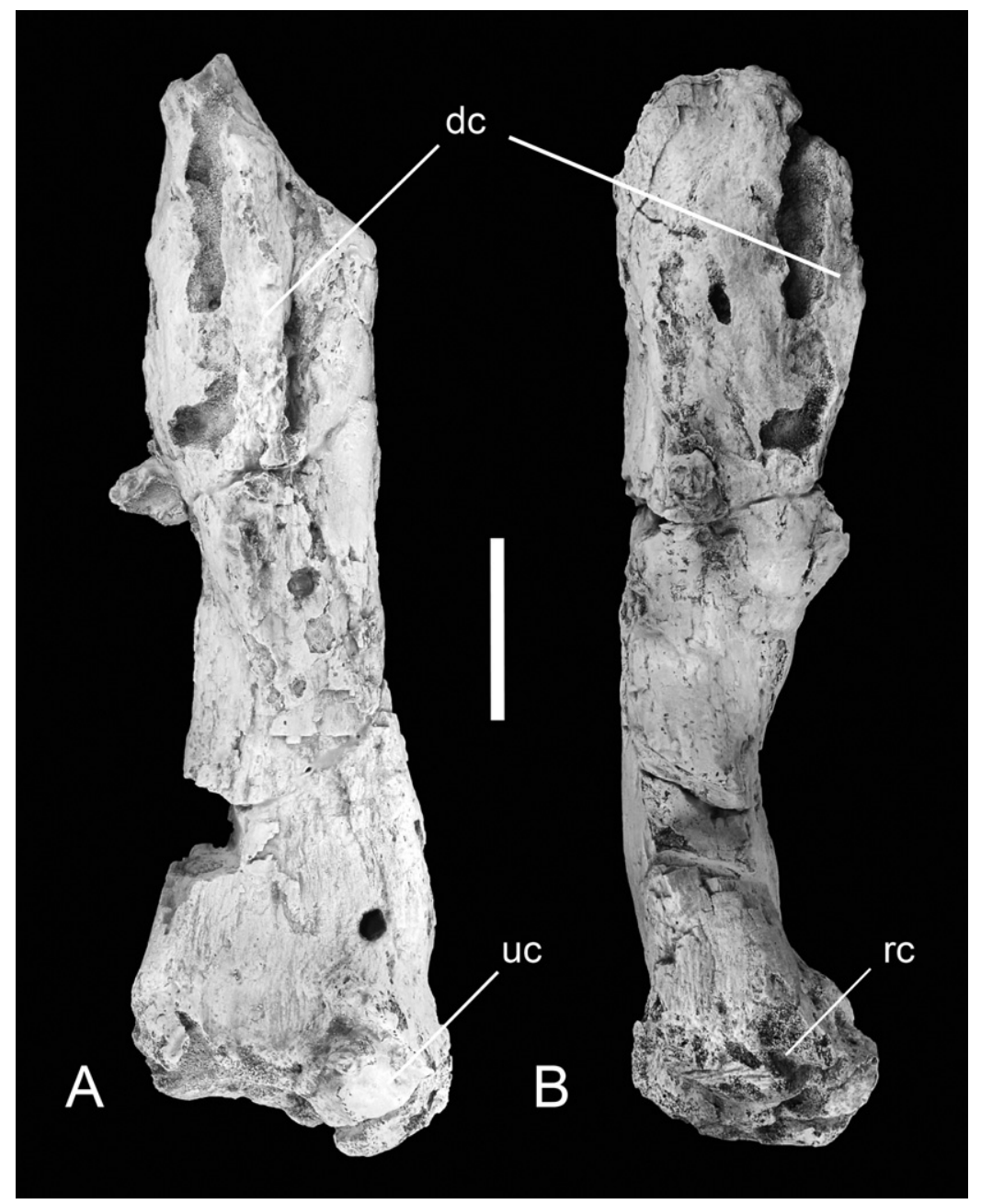

Fig. 5. Arenysaurus ardevoli nov. gen. et sp. from the Late Maastrichtian of Huesca, Spain. Right humerus MPZ2008/336 (paratype) in anterior (A) and lateral (B) views. Abbreviations: dc: deltopectoral crest; rc: radial condyle; uc: ulnar condyle. Scale equals to $50 \mathrm{~mm}$.

Fig. 5. Arenysaurus ardevoli nov. gen. et sp. du Maastrichtien supérieur de Huesca, Espagne. Humérus droit MPZ2008/336 (paratype) en vues antérieure (A) et latérale (B). Abréviations : dc : crête deltopectorale ; rc : condyle radial ; uc : condyle ulnaire. Échelle : $50 \mathrm{~mm}$.

subvertical prefrontal flange), as typically in lambeosaurines $[19,26]$.

The prefrontal participates in the formation of the platform that supports the nasal articulation. This participation is smaller than in the Asian lambeosaurines Amurosaurus and Jaxartosaurus [16] and is rather comparable to the condition observed in corythosaurins [9]. The prefrontal joins with the anterior process of the postorbital to exclude the frontal from the dorsal orbital rim. The medial margin of the prefrontal forms a subvertical flange that extends posteriorly over the dorsal surface of the frontal and above the postorbital joint in lateral view (Fig. 3C).

The frontals are very short, wider than long (length approximately half the maximum width). They are not completely fused together and meet in the midline to form a very prominent median dome, more developed than in other adult lambeosaurines [8,17]. Anterolaterally, the frontal joins with the prefrontal to form together an excavated and steeply sloping rostral platform. This structure is strongly grooved to provide support for the base of the hollow crest. A median cleft is present between the anterior processes of the frontals, as is characteristic of lambeosaurines but Parasaurolophus [9]. The rostral platform is narrower than the posterior part of the bone, as in Amurosaurus and Jaxartasaurus and in contrast to adult corythosaurins [16,17]. This platform does not extend posteriorly above the rostral part of the parietal and of the supratemporal fenestra, unlike Charonosaurus and Parasaurolophus [13,17]. 
The dorsolateral surface of the frontals is slightly depressed but it does not form cup-shaped depression areas as in Sahaliyania [17].

The hourglass-shaped parietals are short anteroposteriorly, with a proximal width that is greater than the length. They articulate with the frontals along a transverse, highly interdigitate suture mediated by a short process into the interfrontal joint (or interparietal process; [19]). The midline ridge is only modestly downwarped and its dorsal margin is approximately at the level with the skull roof and not below the level of the postorbital-squamosal bar, unlike Amurosaurus and derived lambeosaurines $[8,17]$. The sagittal crest is relatively short and narrows posteriorly. The parietal is apparently excluded from the occipital surface of the skull, as typically in Parasaurolophini [13]. The supratemporal fenestrae are small and subovoid, slightly longer anteroposteriorly than wide. They more closely resemble those of Jaxartosaurus [16].

The dorsal surface of the postorbital is nearly flat; it does not form a dorsal promontorium as in parasaurolophins (probably related to the backward extension of the supracranial crest [13]). The postorbitalsquamosal joint reaches a point at mid-length of the supratemporal fenestra. In dorsal view, the transverse width of the skull in the postorbital region is broad, with a width roughly maintained from the orbital region to the squamosal corner (Fig. 3A).

The right squamosal is robust and convex dorsally. The lateral bar is short and low above the cotyloid cavity; the median ramus is lower than the paroccipital process, in contrast to all known lambeosaurines except Tsintaosaurus and Jaxartosaurus $[8,16,17,36]$. The prequadratic (precotyloid) process is short, only slightly longer than the anteroposterior width of the quadrate cotylus, and nearly vertical (Fig. 3C). The squamosals are well exposed in occipital view and extend medially above the supraoccipital in the midline; they have an extensive contact with each other (intersquamosal joint).

The supraoccipital is excluded from the foramen magnum (Fig. 3B). Its ventral margin is horizontal, with a ridge developed along the supraoccipital-exoccipital suture. The posterior surface of the supraoccipital is inclined steeply forward at approximately $45^{\circ}$. The supraoccipital-exoccipital shelf is poorly developed and does not roof the occiput above the foramen magnum.

The exoccipital and opisthotic are completely fused together. Only the right paroccipital process is complete. It is long and slender, hook-like and lateroventrally directed. The paroccipital process descends to the level of the ventral surface of the basioccipital.
The occipital condyle is damaged. The left alar process of the basipterygoid is small and asymmetrical. The basipterygoid processes are elongate and project ventrolaterally; they diverge from the base of the basisphenoid at an angle of $60^{\circ}$ from each other. The cultriform process of the parasphenoid is extended anteriorly, with an unexpanded distal tip. This process is approximately as long as the width across the basipterygoid processes.

The arrangement of the cranial foramina is similar to that seen in hadrosaurids [26] (Fig. 3C). The trigeminal (V) and auditory (VIII) foramina are the largest ones; between them, the lateral wall of the braincase is pierced by a single foramen (for the facial nerve VII). Posterior to the trigeminal foramen and separated from it by a crista, there are two foramina for transmission of the hypoglossal (XII) and of the vagus (X) and glossopharyngeal (IX) nerves, respectively. In the anterolateral part of the braincase, the foramen for the oculomotor (III) and abducens (VI) nerves is larger than the one for the optic (II) nerve.

In addition to the holotype skull, two maxillary fragments (MPZ2008/256-257) have been found in nearly association to it and are here referred to Arenysaurus. The ectopterygoid ridge seems very prominent on the lateral side of the maxilla. A maxillary foramen is present on the dorsal surface of the bone along the maxilla-premaxilla suture, as is common in derived hadrosaurids [17].

\subsubsection{Mandible}

It is represented by a left dentary (MPZ2008/258) and a right surangular (MPZ2008/259) that were found in the same area near the skull. The dentary (length $445 \mathrm{~mm}$ ) preserves the whole row of alveoli but only a small portion of the dental battery (12 teeth) (Fig. 4). The dorsal and ventral borders are subparallel. The anterior portion of the dentary is modestly deflected ventrally, forming an angle of about 15 to $20^{\circ}$ relative to the longitudinal axis of the bone. This morphology is different from that of the Asian lambeosaurines Amurosaurus, Sahaliyania and Tsintaosaurus [17,36], where the dentary is more strongly deflected anteroventrally (also observed in the European taxon Koutalisaurus [29]). The diastema between the articular surface for the predentary and the first dentary tooth is moderate, less than one-third of the length of the tooth row. Among lambeosaurines, only Tsintaosaurus exhibits a long diastema [36]. The coronoid process of Arenysaurus is mostly composed of the dentary; this process is robust, slightly inclined anteriorly and curved inwards. As commonly in hadrosaurids, the distal extension of the tooth row terminates posterior to the apex of the coronoid process. The articulation facet for the splenial indicates that this bone extended about a third the length of the dentary. The number of tooth 
positions in the dentary tooth row is 37 . The surangular lacks a foramen, as is typical in hadrosaurids $[19,35]$.

In addition to the teeth preserved in the dentary, several isolated teeth have also been found. The dentary crown teeth from the middle of the tooth row are elongated lanceolate-shaped, with a height/width ratio of approximately 3:15 (Fig. 4). They possess a prominent median carina and a faint secondary ridge in the mesial side of the crown. The carina is slightly sinuous, as commonly in lambeosaurines [13,17].

The dentary of Arenysaurus is different from that of Koutalisaurus [29] in having a shorter and less medially projecting edentulous portion. It differs from the dentary of a lambeosaurine-like hadrosaurid from Blasi 1 (MPZ99/665) [20] by a greater number of tooth row positions and by the presence of a secondary ridge in the dental crowns, mesial to the median carina, which is absent in those from Blasi 1. The dentary of Arenysaurus also differs from that found in the Latest Maastrichtian of Fontllonga, in Lleida [4] in having a tooth row with a greater number of tooth positions and that terminates posterior to the apex of the coronoid process; this process is anteriorly inclined in Arenysaurus, instead of subvertical in the Fontllonga dentary.

\subsection{Postcranial skeleton}

Many of the postcranial bones referred to Arenysaurus were found disarticulated but in reasonably close association with the skull. They consist of parts of the axial skeleton, including cervical and dorsal vertebrae with ribs, an incomplete sacrum and a large portion of the caudal series (Fig. 4 in [20]); the appendicular skeleton is represented by bones of the pectoral girdle (right scapula and coracoid), forelimb (right humerus), pelvic girdle (right ilium and pubis) and hindlimb (left and right femora).

Seven isolated postaxial cervical vertebrae and three cervical ribs are known. As typically in hadrosaurids [19], the centra are short (length less than the height of the neural arch) and strongly opisthocoelous. The postzygapophyseal processes are long and dorsally arched; they extend well above the level of the neural canal. The posteriormost cervicals exhibits a low but prominent neural spine. The dorsal region is very incompletely known: only one isolated vertebra and two ribs have been discovered. The dorsal neural spine is elongate, approximately 3.5 times the centrum height. As preserved, the partial sacrum consists of five fused vertebrae. The sacral neural spines are broken but they seem relatively elongate. Indeed, the anteriormost caudal vertebrae have long neural spines that are more than three times the height of the centrum, as in lambeosaurines [19]. About two thirds of the caudal region is preserved, including 14 anterior articulated vertebrae. The chevrons are directed posteroventrally at an angle equivalent to the posterodorsal angle of the long neural spines. Fragmentary ossified tendons have been found in close association with the sacrum.

The right scapula is represented by a proximal fragment and an almost complete blade corresponding to a single specimen (estimated length: $525 \mathrm{~mm}$ ). It is typically hadrosaurid in having a narrow proximal end, an acromion process that projects horizontally, a notched anteroventral corner, and a restricted articulation for the coracoid [19]. The dorsal and ventral margins of the scapula are slightly curved and divergent; distally, the blade is approximately $60 \%$ wider than the proximal neck. As is common in hadrosaurids, the coracoid hook is prominent and pointed anteroventrally, and the biceps tubercle is large and projects laterally $[17,19]$. The incomplete right humerus (preserved length $300 \mathrm{~mm}$ ) of Arenysaurus differs from that of other lambeosaurines in that the distal width is greater that the maximum width at the level of the deltopectoral crest because the latter is oriented anteriorly (Fig. 5). The anterior projection of the deltopectoral crest of Arenysaurus resembles the condition found in the hadrosaurine Wulagasaurus [17].

The iliac peduncle of the pubis is a prominent, dorsally directed process. The prepubic blade is dorsoventrally expanded and looks nearly symmetrical. As is typical in hadrosaurids, the femur (length $711 \mathrm{~mm}$ ) has a massive shaft, straight in lateral view, and a developed intercondylar extensor groove that is closed forming a funnel [19].

\subsection{Ontogenetic stage}

The braincase of Arenysaurus is fully ossified; the absence of open cranial sutures indicates that the holotype skull MPZ2008/1 is not from a juvenile [7]. The development of the frontal platform, the absence of a prefrontal-frontal "clamp", the interdigitate suture between the frontals and parietals, and the fusion of the supraoccipital to the skull roof support this interpretation $[10,16,19]$. On the other hand, the skull probably does not belong to an old individual as there is no complete fusion of the frontals [17]. The nature of most of the sutures together with the size of the skull suggests that it represents an adult individual. In addition to the skull, the transverse processes and neural arches are fused to the centra of the vertebrae, and the sacral centra are fused together, as usually in mature hadrosaurid individuals. 
On the basis of lambeosaurine skeletal reconstructions [19], the estimated body length of Arenysaurus is about 5 to $6 \mathrm{~m}$.

\section{Phylogenetic analysis}

In order to determine the systematic position of Arenysaurus within the Hadrosauridae, a phylogenetic analysis was conducted (Fig. 6). Arenysaurus was scored and included in a data matrix of 57 characters and 22 taxa. The matrix is mostly based on the dataset of Godefroit et al. [17], probably the most comprehensive analysis of hadrosaurid phylogeny published to date. For this analysis, one character (number 57, as defined by Evans and Reisz [8]; Appendix) and two taxa (Arenysaurus, Telmatosaurus) have been included in the data matrix; one taxon (Sahaliyania) has not been considered because its inclusion resulted in ambiguity in the results of our analysis (Table 1). Characters for Telmatosaurus were scored from available publications $[6,13,19,29,35]$ and personal observations (BMNH R3386 and additional remains housed at London [6]). The non-hadrosaurid member of Hadrosauroidea Bactrosaurus johnsoni has been used as outgroup [11]. The taxa have been treated at the generic level; the type species has been chosen as representative for multispecific genera (with the exception of Saurolophus, [17]). The matrix was analysed using heuristic searches in PAUP 4.0b10 [33]. Of 57 characters, 44 are binary, five are unordered multistate and eight are ordered multistate characters ([17], Appendix A). This analysis resulted in a single parsimonious tree of 84 steps $(\mathrm{CI}=0.893$; $\mathrm{RI}=0.960$; Fig. 6). The overall tree topology presented here is similar to that previously published by recent works $[8,17]$. Bootstrap values (1000 bootstrap replicates completed) are indicated in the caption of Fig. 6.

Arenysaurus may be regarded as a rather basal lambeosaurine, the sister-taxon for Amurosaurus and a monophyletic group formed by the Corythosaurini and Parasaurolophini. It shares with the Lambeosaurinae (Fig. 6: node J) a shortened parietal, with a ratio length/minimal width less than 2 (character 2 ), a sinuous median carina of dentary teeth (character 43) and elongate sacral (and anteriormost caudal) neural spines, more than three times the centrum height (character 45) (the last two characters are ambiguous, only supported by ACCTRAN or accelerated optimisation). Arenysaurus shares with all lambeosaurines but Aralosaurus (Fig. 6: node K) a prefrontal participating in the lateroventral border of the hollow crest (character 22). Moreover, Arenysaurus shares with Jaxartosaurus, Amurosaurus and other derived lambeosaurines (Fig. 6:

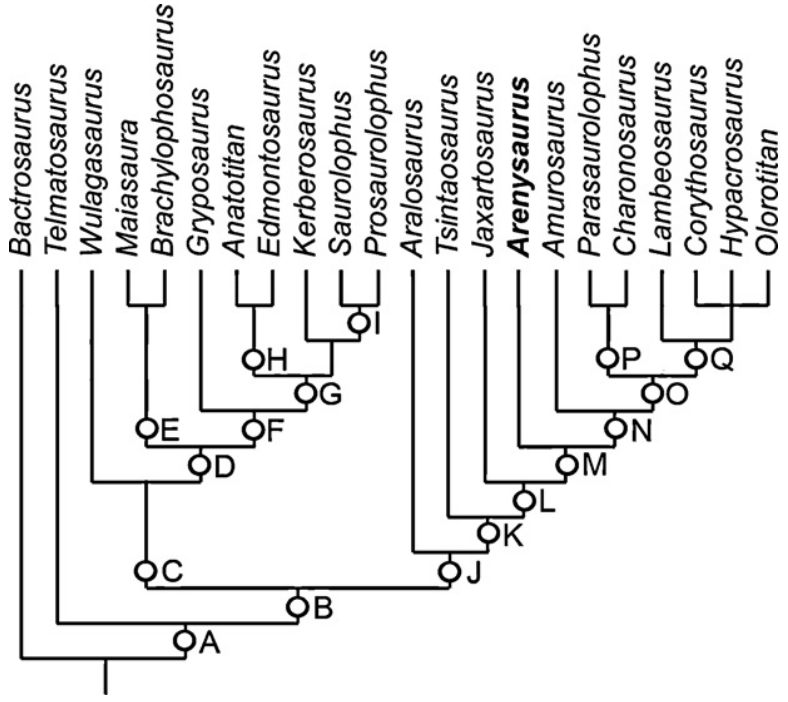

Fig. 6. Phylogenetic relationships of Arenysaurus within the Hadrosauridae. Letters indicate nodes; bs: bootstrap value. Characters are followed by an "a" when supported only by ACCTRAN (accelerated optimisation), and by a "d" when supported only by DELTRAN (delayed optimisation). List of apomorphies (Appendix A): Node A (Hadrosauridae): 9, 21, 30(1), 34, 36, 40(1)a, 42a, 44a, 46, 47a, 50a, 51a, 52a, 53(1)a; Node B (Euhadrosauria; bs =100): 25, 29, 31(1), 33, 37, 39, 40(1)d, 42d, 44d, 47d, 50d, 51d, 52d, 53(1)d; Node C (Hadrosaurinae; bs =91): 10(1)a, 12a, 17(1)a, 32, 53(2); Node D (bs =71): 3, 10(1)d, 12d, 17(1)d; Node E (bs = 85): 20(1), 24, 31(2), 40(2), 56; Node F (bs =91): 10(2), 26, 30(2); Node G (bs = 89): 16(1), 17(2); Node H (bs=95): 10(2), 27; Node I (bs=55): 20(2); Node J (Lambeosaurinae; bs =94): 2, 6, 11a, 16(2)a, 19(1)a, 30(1)a, 35, 43a, 45a, 48a, 49a; Node K (bs = 85): 22, 30(1), 43d, 45d, 48d, 49da; Node L (bs =69): 8(1), 13a, 18a; Node M (bs = 74): 57; Node N (bs = 59): 4; Node O (bs =70): 11d, 13d, 16(2)d, 18, 19; Node P (Parasaurolophini; bs =98): 8(2), 28, 54, 55; Node Q (Corythosaurini; bs =60): 14 .

Fig. 6. Relations phylogénétiques d'Arenysaurus au sein des Hadrosauridae. Les noeuds sont indiqués par des lettres; bs =valeur bootstrap. Les caractères suivis d'un « $\mathrm{a}$ » sont uniquement soutenus par l'optimisation ACCTRAN, tandis que ceux suivis d'un «d» sont uniquement soutenus par l'optimisation DELTRAN. Liste d'autapomorphies (voir Appendice A) : Noeud A (Hadrosauridae) : 9, 21, 30(1), 34, 36, 40(1)a, 42a, 44a, 46, 47a, 50a, 51a, 52a, 53(1)a ; Noeud B (Euhadrosauria; bs = 100) : 25, 29, 31(1), 33, 37, 39, 40(1)d, 42d, 44d, 47d, 50d, 51d, 52d, 53(1)d; Noeud C (Hadrosaurinae; bs =91) : 10(1)a, 12a, 17(1)a, 32, 53(2); Noeud D (bs=71) : 3, 10(1)d, 12d, 17(1)d ; Noeud E (bs = 85) : 20(1), 24, 31(2), 40(2), 56; Noeud F (bs = 91) : 10(2), 26, 30(2); Noeud G (bs = 89) : 16(1), 17(2); Noeud H (bs = 95) : 10(2), 27 ; Noeud I (bs = 55) : 20(2) ; Noeud J (Lambeosaurinae ; bs =94) : 2, 6, 11a, 16(2)a, 19(1)a, 30(1)a, 35, 43a, 45a, 48a, 49a ; Noeud K (bs = 85) : 22, 30(1), 43d, 45d, 48d, 49da; Noeud L (bs = 69) : 8(1), 13a, 18a; Noeud M (bs =74) : 57; Noeud N (bs = 59) : 4; Noeud $\mathrm{O}(\mathrm{bs}=70): 11 \mathrm{~d}, 13 \mathrm{~d}, 16(2) \mathrm{d}, 18,19$; Noeud P (Parasaurolophini ; bs =98) : 8(2), 28, 54, 55 ; Noeud Q (Corythosaurini ; bs =60) : 14 .

node $\mathrm{L}$ ) the presence of a deeply excavated frontal platform (character 8.1). Arenysaurus is the sister-taxon of the monophyletic group formed by Amurosaurus and the Corythosaurini plus Parasaurolophini clade 
Table 1

Data matrix (57 characters, 22 taxa) used for the phylogenetic analysis of Arenysaurus ardevoli (based on [17]).

Tableau 1

Matrice de données (57 caractères, 22 taxons) utilisée lors de 1'analyse phylogénétique d'Arenysaurus ardevoli (d'après [17]).

\begin{tabular}{|c|c|c|c|c|c|c|c|c|c|c|c|c|}
\hline & $1-5$ & $6-10$ & $11-15$ & $16-20$ & $21-25$ & $26-30$ & $31-35$ & $36-40$ & $41-45$ & $46-50$ & $51-55$ & $56-57$ \\
\hline Bactrosaurus & 00000 & 00000 & 00000 & 00000 & 00000 & 00000 & 00000 & 00000 & 00000 & 00000 & 00000 & 00 \\
\hline Telmatosaurus & 00000 & 00010 & X0000 & 00000 & $100 ? 0$ & $0 ? ? 02$ & 00010 & $1000 ?$ & $0 \times 0 ? ?$ & $1 ? ? 0 ?$ & $? ? ? ? ?$ & $? 0$ \\
\hline Aralosaurus & $? 1 ? 00$ & $100 ? ?$ & ????? & $? ? 0 ? 0$ & $101 ? 1$ & $0001 ?$ & $? 0111$ & $11 ? ? ?$ & ????? & $? ? ? ? ?$ & $? ? ? ? ?$ & $? 0$ \\
\hline Tsintaosaurus & 01001 & 10010 & $? ? 0 ? ?$ & $? ? 030$ & 11001 & 00011 & 10111 & 11211 & 11111 & 11111 & 11100 & 00 \\
\hline Jaxartosaurus & 01001 & $101 ? ?$ & $? ? ? ? ?$ & $? ? ? ? 0$ & 11001 & $0001 ?$ & ????? & ????? & ????? & ????? & ????? & $? 0$ \\
\hline Amurosaurus & 01011 & $101 ? ?$ & ????? & ????0 & 11101 & 00011 & 10111 & $1111 ?$ & $111 ? ?$ & 11111 & 11100 & 01 \\
\hline Corythosaurus & 01011 & 11110 & 10110 & 20120 & 11101 & 00011 & 10111 & 11111 & 21111 & 11111 & 11100 & 01 \\
\hline Hypacrosaurus & 01011 & 11110 & 10110 & 20120 & 11101 & 00011 & 10111 & 11111 & 21111 & 11111 & 11100 & 01 \\
\hline Olorotitan & 01011 & 11110 & 10110 & 20120 & $11 ? ? 1$ & $0 ? ? 11$ & 10111 & $1111 ?$ & 21111 & 11111 & 11100 & $0 ?$ \\
\hline Lambeosaurus & 01011 & 11110 & 10110 & 20110 & 11101 & 00011 & 10111 & 11111 & 21111 & 11111 & 11100 & 01 \\
\hline Parasaurolophus & 11011 & 12210 & 10100 & 20110 & 11101 & 00111 & 10111 & 11111 & 21111 & 11111 & 11111 & 01 \\
\hline Charonosaurus & 11011 & $112 ? ?$ & $? ? ? ? ?$ & $? ? ? ? 0$ & 11101 & 00111 & 10111 & $1111 ?$ & $? 1111$ & 11111 & 11111 & $0 ?$ \\
\hline Wulagasaurus & $? 00 ? ?$ & $? ? ? ? ?$ & $? ? ? ? ?$ & $? ? ? ? ?$ & $? ? ? ? 1$ & 0???? & $? 1 ? 1 ?$ & $? ? 11 ?$ & $? ? ? ? ?$ & $? ? 00 ?$ & $? ? 2 ? ?$ & $? ?$ \\
\hline Maiasaura & 00100 & 00011 & 01000 & 01001 & 10011 & 00012 & 21110 & 11112 & 21010 & 11001 & 11200 & 10 \\
\hline Brachylophosaurus & 00100 & 00011 & 01001 & 01001 & 10011 & 00012 & 21110 & 11212 & 21010 & 11001 & 11200 & 10 \\
\hline Gryposaurus & 00100 & 00012 & 01001 & 01000 & 10001 & 10013 & 11110 & 11111 & 21010 & 11001 & 11200 & 00 \\
\hline Kerberosaurus & $001 ? 1$ & $000 ? ?$ & $? ? ? ? ?$ & $? 2 ? ? 0$ & 10001 & $1 ? 013$ & 11110 & $11 ? ? ?$ & $2 ? 0 ? ?$ & $11 ? ? ?$ & $? ? ? ? ?$ & 00 \\
\hline Saurolophus & 00101 & 00012 & 01001 & 12002 & 10001 & 10013 & 11110 & 11211 & $31 ? 10$ & 11001 & 11200 & $? 0$ \\
\hline Prosaurolophus & 00101 & 00012 & 01001 & 12002 & 10001 & 10013 & 11110 & 11211 & 21010 & 11001 & 11200 & 00 \\
\hline Anatotitan & 00100 & 00013 & 01001 & 12000 & 10001 & 11013 & 11110 & 11311 & 31010 & 11001 & 11200 & 00 \\
\hline Edmontosaurus & 00100 & 00013 & 01001 & 12000 & 10001 & 11013 & 11110 & 11311 & 31010 & 11001 & 11200 & 00 \\
\hline Arenysaurus & 11001 & ?11?? & $? ? ? ? ?$ & $? ? ? ? ?$ & 11001 & $000 ? ?$ & $? ? 11 ?$ & $? ? 11 ?$ & $111 ? 1$ & $11 ? ? ?$ & ????? & $? 1$ \\
\hline
\end{tabular}

Two taxa (Arenysaurus and Telmatosaurus) have been incorporated, whereas one taxon from the original matrix (Sahaliyania) has not been included in the analysis. Values: ? = missing data; $0-2=$ character states; $\mathrm{X}=$ variable within the taxon $(0-1)$.

Deux taxons (Arenysaurus et Telmatosaurus) ont été ajoutés, tandis qu'un taxon de la matrice originelle (Sahaliyania) n'a pas été pris en compte dans l'analyse. Valeurs : ?= données manquantes ; 0-2=états des caractères ; X=variable au sein du taxon (0-1).

(Fig. 6: node M); they share a prefrontal that extends over the dorsal surface of the frontal and above the prefrontal-postorbital joint in lateral view (character 57). Arenysaurus lacks the only unambiguous synapomorphy of the clade formed by Amurosaurus, corythosaurins and parasaurolophins (Fig. 6: node N): the midline of the parietal is not strongly downwarped to below the level of the postorbital-squamosal bar (character 4). In Arenysaurus, the median ramus of the squamosal is lower than the paroccipital process (character 23), unlike Amurosaurus, corythosaurins and parasaurolophins (also present in Aralosaurus) [17]. Arenysaurus is not a derived lambeosaurine as its dental battery ( 37 tooth positions) lacks the condition observed in parasaurolophins and corythosaurins (42-45 tooth positions; character 41 ). The presence of a very shortened frontal, with a posterior length/maximal width that is less than 0.6 (character 7), is here interpreted as convergently acquired in Arenysaurus and in derived lambeosaurines. The parasaurolophin clade formed by Parasaurolophus and Charonosaurus is defined by four synapomorphies (Fig. 6: node P), including a frontal platform extending above the anterior portion of the supratemporal fenestra (character 8), and a dorsal promontorium on the postorbital (character 28). In Arenysaurus, the parietal does not participate in the occipital aspect of the skull, as is the case in Parasaurolophus and Charonosaurus [17]. This condition is regarded as convergently developed in Arenysaurus as it lacks the two other synapomorphies of the Parasaurolophini. The corythosaurin clade (composed of Lambeosaurus, Corythosaurus, Hypacrosaurus and Olorotitan; Fig. 6: node Q) is defined by a lateral premaxillary process extending further backward the lacrimal bone (character 14), a condition that cannot be checked in Arenysaurus.

\section{Palaeobiogeographical implications}

In the current state of knowledge, the most basal (and earliest) lambeosaurine hadrosaurids come from Asian localities, which may thus be considered their ancestral area [16,17]: Aralosaurus from the Turonian-Santonian of Kazakhstan, Tsintaosaurus from the Campanian (?) of eastern China, Jaxartosaurus from the Santonian of Kazakhstan, and Amurosaurus from the Maastrichtian of 
eastern Russia [15-17,36]. Other Asian lambeosaurines are derived forms from the Maastrichtian of eastern Russia and northeastern China (Charonosaurus, Olorotitan, Sahaliyania) [12,14,17]. Nipponosaurus is known from the Santonian-Early Campanian of the Sakhalin Island (now Russia) [32], but its phylogenetic position and status remain controversial $[8,17,19]$. Additional research is needed to further clarify the phylogenetic position of the poorly known lambeosaurine-like taxa Barsboldia from the Maastrichtian of Mongolia [22] and Nanningosaurus from an undetermined Late Cretaceous locality of southern China [23]. In western North America, all known lambeosaurines are derived forms that belong to the clade composed of corythosaurins and parasaurolophins (i.e., Corythosaurus, Hypacrosaurus, Lambeosaurus, Velafrons and Parasaurolophus) [10,19]. Their oldest well-dated taxa come from the Campanian [34]. The presence of an "unidentifiable lambeosaurine" in the Turonian of Alaska [21] is doubtful and needs to be confirmed ([27]; A. Pasch, pers. comm.).

The presence of lambeosaurines in the Maastrichtian of southwestern Europe (Ibero-Armorican Realm) has been recently evoked $[3,5,28]$, but most of the finds do not include significant cranial material. The relatively basal phylogenetic position of Arenysaurus among lambeosaurines contrasts with its late stratigraphic distribution. Such incongruent distribution can be explained by inferring ghost lineage durations [17,24]. If sister taxa share the same time of origin, it is possible to establish the minimal age for the origin of the lineage leading to Arenysaurus: its origin cannot occur later than the first occurrence of its sister-taxon, i.e. the clade consisting of Amurosaurus and the Corythosaurini plus Parasaurolophini. This means that the Arenysaurus lineage may have diverged from that leading to more advanced Asian lambeosaurines no later than the Middle Campanian, yielding a ghost lineage duration of approximately 10 to 12 millions years.

The discovery of a rather basal lambeosaurine in the Maastrichtian of the Iberian Peninsula and the palaeobiogeographical history of lambeosaurines may suggest a late dispersal event from Asia to Europe during the second half of the Late Cretaceous. Palaeogeographical reconstructions, however, indicate that the opening of the Turgai Strait, an epicontinental seaway located at the east of the Ural Mountains, apparently provided a barrier to dispersal between Asia and Europe after the Cenomanian [30]. The close relationships between European and Asian lambeosaurines shows that such a barrier does not seem to have been effective in preventing faunal exchange of lambeosaurine hadrosaurids between Asia and Europe during the Late Cretaceous.

\section{Conclusions}

Arenysaurus ardevoli is a new lambeosaurine hadrosaurid from the Late Maastrichtian of Aren (Huesca, Spain). It is the first hadrosaurid taxon erected from the Late Cretaceous of the Iberian Peninsula on the basis of significant cranial material. Arenysaurus is characterized by possessing a frontal dome more prominent than in other adult lambeosaurines together with subvertical prequadratic (precotyloid) process of the squamosal and jugal process of the postorbital, and a deltopectoral crest of the humerus oriented anteriorly. It also differs from other hadrosaurids in combining short frontals, approximately two times wider than long; parietal with a midline ridge at the level of the postorbital-squamosal bar; parietal excluded from the occiput; and median ramus of squamosal lower than the paroccipital process.

Arenysaurus occupies a rather basal position within the Lambeosaurinae as the sister-taxon to Amurosaurus and a monophyletic group composed of the Corythosaurini plus Parasaurolophini, presumably splitting from the Asian taxa no later than the Middle Campanian. This suggests a palaeogeographical connection between Asia and Europe during the Late Cretaceous.

\section{Acknowledgements}

Financial support provided by the Ministerio de Educación y Ciencia of Spain (projects CGL 200403393, 2007-62469, 2007-64061, 2005-07878-C02-02 and 2008-06533-C03-02), Gobierno de Aragón (Grupos Consolidados 2008, Departamento de Educación y Cultura; JIC, PCC), Gobierno Vasco/EJ (research group GIC07/14-361; XPS) and Principado de Asturias (Protocolo CN-04-226; JIR-O). The excavations and restoration of the fossils have been subsidized by the Gobierno de Aragón, Diputación Provincial de Huesca and Ayuntamiento de Aren. Many thanks to S. Chapman, A.C. Milner (BMNH, London), P. Godefroit and P. Lauters (IRSNB/KBIN, Brussels) for kindly providing access to the collections under their care, A. Pasch (Anchorage, AK) for the information facilitated to us, the Institut d'Estudis Ilerdencs (IEI), the Associació Ilerdenca de Paleontologia (AIP), and two anonymous referees for their helpful comments. Photographs were made by Z. Herrera (Univ. Zaragoza). Palaeomagnetic measurements were carried out at the Institut de Ciències de la Terra (SCT Universitat de Barcelona - CSIC). 
Dr. R. Royo-Torres assisted part of the palaeomagnetic sampling.

\section{Appendix A. Supplementary data}

Supplementary data (Fig. S1, S2) with online version of this article available on http://www.sciencedirect.com and doi:10.1016/j.crpv.2009.05.002.

\section{References}

[1] L. Ardèvol, J. Klimowitz, J. Malagón, P.J. Nagtegaal, Depositional sequence response to foreland deformation in the Upper Cretaceous of the Southern Pyrenees, Spain, Bull. Amer. Assoc. Petrol. Geol. 84 (2000) 566-587.

[2] S.C. Cande, D. Kent, Revised calibration of the geomagnetic polarity time scale for the Late Cretaceous and Cenozoic, J. Geophys. Res. 100 (1995) 6093-6095.

[3] M.L. Casanovas, X. Pereda-Suberbiola, J.V. Santafé, D.B. Weishampel, First lambeosaurine hadrosaurid from Europe: palaeobiogeographical implications, Geol. Mag. 136 (1999a) 205-211.

[4] M.L. Casanovas, X. Pereda-Suberbiola, J.V. Santafé, D.B. Weishampel, A primitive euhadrosaurian dinosaur from the Uppermost Cretaceous of the Ager syncline (southern Pyrenees, Catalonia), Geol. Mijnbouw 78 (1999b) 345-556.

[5] P. Cruzado-Caballero, J.I. Canudo, J.I. Ruiz-Omeñaca, Nuevas evidencias de la presencia de hadrosaurios lambeosaurinos (Dinosauria) en el Maastrichtiense superior de la Península Ibérica (Arén, Huesca), Geogaceta 38 (2005) 47-50.

[6] F. Dalla-Vecchia, Telmatosaurus and the other hadrosaurids of the Cretaceous European archipelago. An overview, Natura. Nascosta 32 (2006) $1-55$.

[7] D.C. Evans, C.A. Forster, R.R. Reisz, The type specimen of Tetragonosaurus errectofrons (Ornithischia: Hadrosauridae) and the identification of juvenile lambeosaurines, in: P.J. Currie, E.B. Koppelhus (Eds.), Dinosaur Provincial Park, Indiana Univ. Press, Bloomington, Indianapolis, 2005, pp. 349-365.

[8] D.C. Evans, R.R. Reisz, Anatomy and relationships of Lambeosaurus magnicristatus, a crested hadrosaurid dinosaur (Ornithischia) from the Dinosaur Park Formation, Alberta, J. Vert. Paleontol. 27 (2007) 373-393.

[9] D.C. Evans, R.R. Reisz, K. Dupuis, A juvenile Parasaurolophus (Ornithischia: Hadrosauridae) braincase from Dinosaur Provincial Park, Alberta, with comments on crest ontogeny in the genus, J. Vert. Paleontol. 27 (2007) 642-650.

[10] T.A. Gates, S.D. Sampson, C. Delgado de Jesús, L.E. Zanno, D. Eberth, R. Hernández-Rivera, et al., Velafrons coahuilensis, a new lambeosaurine hadrosaurid (Dinosauria: Ornithopoda) from the Late Campanian Cerro del Pueblo Formation, Coahuila, Mexico, J. Vert. Paleontol. 27 (2007) 917-930.

[11] P. Godefroit, Z.-M. Dong, P. Bultynck, H. Li, L. Feng, New Bactrosaurus (Dinosauria: Hadrosauroidea) material from Iren Dabasu (Inner Mongolia, P.R. China), Bull. Inst. R. Sci. Nat. Belg. Sci. Terre 68 (Suppl.) (1998) 3-70.

[12] P. Godefroit, S. Zan, L. Jin, Charonosaurus jiayinensis n.g., n.sp., a lambeosaurine dinosaur from the Late Maastrichtian of northeastern China, C. R. Acad. Sci. III 330 (2000) 875-882.

[13] P. Godefroit, S. Zan, L. Jin, The Maastrichtian (Late Cretaceous) lambeosaurine dinosaur Charonosaurus jiayinensis from north- eastern China, Bull. Inst. R. Sci. Nat. Belg. Sc. Terre 71 (2001) 119-168.

[14] P. Godefroit, Y.L. Bolotsky, V. Alifanov, A remarkable hollowcrested hadrosaur from Russia: an Asian origin for lambeosaurines, C. R. Palevol 2 (2003) 143-151.

[15] P. Godefroit, V. Alifanov, Y.L. Bolotsky, Y. A re-appraisal of Aralosaurus tuberiferus (Dinosauria, Hadrosauridae) from the Late Cretaceous of Kazakhstan, Bull. Inst. R. Sci. Nat. Belg. Sc. Terre 74 (suppl.) (2004) 139-154.

[16] P. Godefroit, Y.L. Bolotsky, J. Van Itterbeeck, The lambeosaurine dinosaur Amurosaurus riabinini, from the Maastrichtian of Far Eastern Russia, Acta. Palaeontol. Pol. 49 (2004) 585-618.

[17] P. Godefroit, S. Hai, T. Yu, P. Lauters, New hadrosaurid dinosaurs from the Uppermost Cretaceous of north-eastern China, Acta. Palaeontol. Pol. 53 (2008) 47-74.

[18] F. Gradstein, J. Ogg, A. Smith, A Geologic Time Scale, Cambridge Univ. Press, Cambridge, 2004 (589 pp.).

[19] J.R. Horner, D.B. Weishampel, C.A. Forster, Hadrosauridae. In: D.B. Weishampel, P. Dodson, H. Osmólska (Eds.), The Dinosauria, 2nd edition, Univ. California Press, Berkeley, USA, 2004, pp. 438-463 (and supplement: www.ucpress.edu/books/pages/2601001/2601001.suplement. html).

[20] N. López-Martínez, J.I. Canudo, L. Ardèvol, X. PeredaSuberbiola, X. Orue-Etxebarria, G. Cuenca-Bescós, et al., New dinosaur sites correlated with Upper Maastrichtian pelagic deposits in the Spanish Pyrenees: implications for the dinosaur extinction pattern in Europe, Cret. Res. 22 (2001) 41-61.

[21] E. Lund, T.A. Gates, A historical and biogeographical examination of hadrosaurian dinosaurs. In: S.G. Lucas, R.M. Sullivan (Eds.), Late Cretaceous vertebrates form the Western Interior, New Mexico Mus. Nat. Hist. Sci. Bull. 35 (2006) 263-276.

[22] T. Maryańska, H. Osmólska, First lambeosaurine dinosaur from the Nemegt Formation, Acta Palaeontol. Pol. 26 (1981) 243-255.

[23] J. Mo, Z. Zhao, W. Wang, X. Xu, The first hadrosaurid dinosaur from southern China, Acta Geol. Sinica 81 (2007) 550-554.

[24] M.A. Norell, Taxic origin and temporal diversity: the effect of phylogeny, in: M. Novacek, Q. Wheelers (Eds.), Extinction and Phylogeny, Columbia Univ. Press, New York, 1992, pp. 89-118.

[25] O. Oms, J.I. Canudo, Datación magnetoestratigráfica de los dinosaurios del Cretácico terminal (Maastrichtiense superior) de Arén (Huesca, Unidad Surpirenaica Central), Geo-Temas 6 (5) (2004) 51-54.

[26] J.H. Ostrom, The cranial anatomy of the hadrosaurian dinosaurs of North America, Bull. Amer. Mus. Nat. Hist. 122 (1961) 33-186.

[27] A.D. Pasch, K.C. May, Taphonomy and paleoenvironment of a hadrosaur (Dinosauria) from the Matanuska Formation (Turonian) in South-central Alaska, in: D.H. Tanke, D.H.K. Carpenter (Eds.), Mesozoic Vertebrate Life Indiana University Press, Bloomington, 2001, pp. 219-236.

[28] X. Pereda-Suberbiola, J.I. Canudo, J. Company, P. CruzadoCaballero, J.I. Ruiz-Omeñaca, Hadrosauroid dinosaurs from the Latest Cretaceous of the Iberian Peninsula, J. Vert. Paleontol 2009;29(3).

[29] A. Prieto-Márquez, R. Gaete, G. Rivas, A. Galobart, M. Boada, Hadrosauroid dinosaurs from the Late Cretaceous of Spain: Pararhabdodon isonensis revisited and Koutalisaurus kohlerorum, gen. et sp. nov., J. Vert. Paleontol. 26 (2006) 929-943 (and supplementary data: www.vertpaleo.org/jvp/JVPcontents.html). 
[30] I. Sanmartín, H. Enghoff, F. Ronquist, Patterns of animal dispersal, vicariance and diversification in the Holarctic, Biol. J. Linnean Soc. 73 (2001) 345-390.

[31] P.C. Sereno, A rationale for phylogenetic definitions, with application to the higher-level taxonomy of Dinosauria, N. Jahrb. Geol. Paläontol. Abh. 210 (1998) 41-83.

[32] D. Suzuki, D.B. Weishampel, N. Minoura, Nipponosaurus sachalinensis (Dinosauria: Ornithopoda): Anatomy and systematic position within Hadrosauridae, J. Vert. Paleontol. 24 (2004) 145-164.

[33] D.L. Swofford, Phylogenetic Analysis Using Parsimony* (and other methods), 4.0b10. Sinaur Associates, Sunderland, Massachusetts, 2002.
[34] D.B. Weishampel, P.M. Barrett, R.A. Coria, J. Le Loeuff, X. $\mathrm{Xu}, \mathrm{X}$. Zhao, et al., Dinosaur distribution, in: D.B. Weishampel, P. Dodson, H. Osmólska (Eds.), The Dinosauria, 2nd ed., Univ. California Press, Berkeley, Los Angeles, 2004, pp. 517-606.

[35] D.B. Weishampel, D.B. Norman, D. Grigorescu, Telmatosaurus transsylvanicus from the Late Cretaceous of Romania: the most basal hadrosaurid dinosaur, Palaeontology 36 (1993) 361-385.

[36] C.C. Young, The dinosaurian remains of Laiyang, Shantung, Palaeontol. Sinica C 16 (1958) 1-138. 